\title{
主流速分布の新計測法
}

\author{
藤田一郎 (神戸大学工学部)，渡辺英樹（神戸大学大学院）。
}

\section{A New Method for Measuring Main Flow Distribution by Using Gradient Tensor on Space-Time Image}

\author{
Ichiro FUJTA and Hideki WATANABE
}

\begin{abstract}
A novel image analysis method for measuring river surface flow is presented. The method utilizes a space-time image of brightness on a searching line set parallel to the main flow direction. The angle of streaky pattern appeared on the space-time image indicates the mean flow velocity at the searching location. The gradient tensors of brightness are used to measure the streaky angle. The presented method, which we call STIV (the space time image velocimetry), is applied to an open-channel surface flow visualized by tracers and the large-scale actual flow of the Uji River. The results indicate that the method has a reasonable accuracy as compared with the conventional PIV.
\end{abstract}

Keywords: River flow measurement, Space-time image, STIV, PIV, Gradient tensor

\section{1. まえがき}

著者らは，河川表面の流速分布を非接触計測する方法 として, テンプレートパターンマッチング法に基づく LSPIV (Large-Scale Particle Image Veloci-metry)1), および時空間画像を利用した STIV(Space-Time Image Velocimetry)を提案してきている ${ }^{2,3}$. 前者は二次元流速 分布を計測する手法であり，後者は，流量観測法として の実用性をさらに高めるために計測対象を主流方向成 分だけに限定して流速の横断分布を計測する方法であ る. 本研究では，STIVにおける解析手法の改良を行う とともに，その計測精度を LSPIV と比較し，その有用 性について検討した.

\section{STIV の概要}

STIV $^{4)}$ は，主として実際河川を対象として一次元（主 流方向）の平均速度場を求める新たな画像計測手法であ る.この方法では，水表面の流れ方向に想定した検査線 上の輝度分布の時間変化を時空間プロットし，そこに現 われる縞パターンの勾配から平均流速を求める。STIV で用いる時空間画像の一例を Fig.1(a)に示す。これは， 縦軸に時間軸，横軸に流れ方向に平行に配置した検查線 をとり，画像の濃度分布の時空間変化を示したものであ
る. 全体的な傾向として右下に向かう縞模様が確認でき る.この縞模様の平均的な傾き $\phi$ を求めれば検査上を通 過している表面流の平均速度が得られることになる。す なわち，検查上の平均的な流速は次式から得られる。

$$
U=\frac{S_{x}}{S_{t}} \tan \phi
$$

ここで, $S x(\mathrm{~m} /$ 画素) : 検查線軸の単位長さスケール, $S_{t}$ (sec/画素)：時間軸の単位時間スケールである. 縞パ ターンの傾きは以下の式から求めることができる5).

$$
\tan 2 \phi=\frac{2 J_{12}}{J_{22}-J_{11}}
$$

ここに, $J_{12}$ などは時空間画像上の輝度勾配に関するテン ソルで

$$
J_{p q}=\int_{A} \frac{\partial f}{\partial x_{p}} \frac{\partial f}{\partial x_{p}} d x d t
$$

から計算できる. $f$ は輝度分布，添え字の $p$ および $q$ は 時空間の成分を表す指数で, ここでは $x_{1}=x$ および $x_{2}=\mathrm{t}$ である，A は輝度勾配值の積分領域である。また，縞模 様のコレーレンシーが次式で定義される. 
$C c=\frac{\sqrt{\left(J_{22}-J_{11}\right)^{2}+4 J^{2}{ }_{12}}}{J_{11}+J_{22}}$

(4)

この值は縞パターンの強さを示すパ ラメータであり，理想的な縞模様の 場合に 1 , 全く縞模様がない場合に 0 の值をとる指標である.

\section{3 . 実験水路による検討}

\section{1 実験方法}

実験には, 長さ $20 \mathrm{~m}$, 幅 $2 \mathrm{~m}$, 水 路床勾配 $1 / 800$ の直線開水路を用い た. 表面流の可視化には, 平均粒径 $20 \mu \mathrm{m}$ のナイロン破砕粒子 (白色粉 末）をトレーサーとして用い，上流 側から均等に散布した，画像の撮影 は水面の鉛直上方から, デジタルビ デオカメラを用いて行った。実験条 件は, $\mathrm{Q}=24.47(\mathrm{l} / \mathrm{s}), \mathrm{h}=7.6(\mathrm{~cm})$, 撮影時間は 30 秒，時間間隔は $1 / 30$ 秒である。解析方法として, STIV 法, PIV 法を行い, 比較検討した.

3.2 時空間プロットとコヒーレンシー分布

Fig.1(a)は，水路の中央部分での連続可視化 画像から得られた時空間画像と式 (2) を用い て得られた勾配ベクトルを重ねて示してある. ここではトレーサーを用いているため非常に明 瞭なパターンが得られており, 縞パターンに対 応した勾配が良好に計算されていることが認め られる. Fig.1(b)には, コヒーレンシーの分布 と勾配ベクトルを重ねて示した. コヒーレンシ 一の值の大きい領域で勾配ベクトルが良好に得 られている. 有意な勾配ベクトルの值はこの特 徵を用いることによって, 正確に算出可能と考 えられる。

\section{3 解析結果}

有意な方向を示した勾配ベクトルのみの平均 を求めるために，あるしきい值以上のコヒーレ ンシーに対応する勾配ベクトルの勾配（ $\tan 2$ 申)の相対度数分布を示したのが Fig.2である. ほぼ対称な分布形を示していることがわかる. 本研究ではこの度数分布の重み付け平均から $\tan 2 \phi$ の平均值を求め, 式(1)から流速值を求め た. なお，度数分布の正規化はここでは行って いない.

このような手順で求めたある横断測線上の平 均流速分布を示したのが Fig.3である. 図には, 比較のために PIV による結果も示した. STIV では 1 画素ピッチで検查線を移動させて求めた

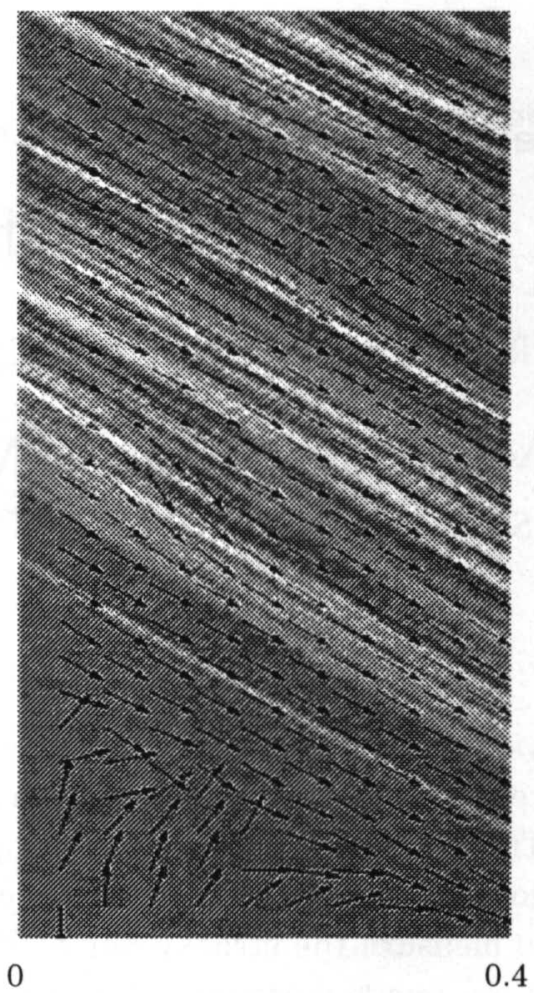

(a)

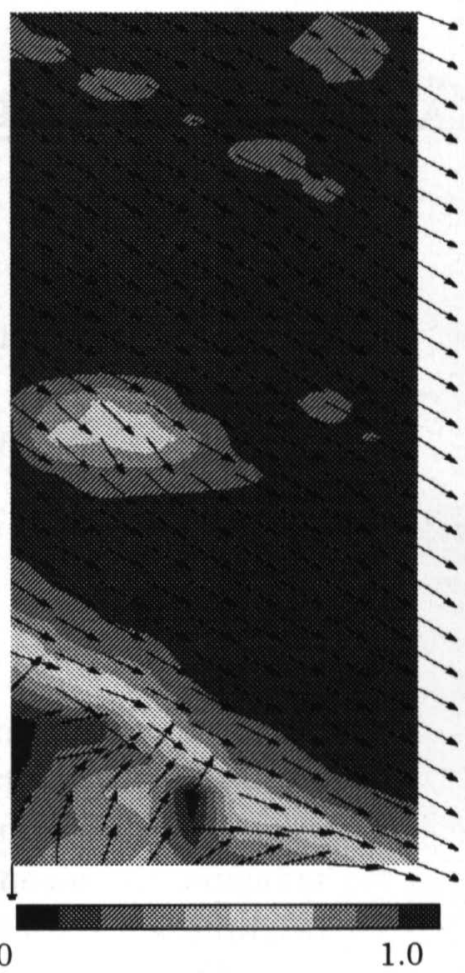

(b)

Fig. 1 Space-time Plot and Coherency Distribution

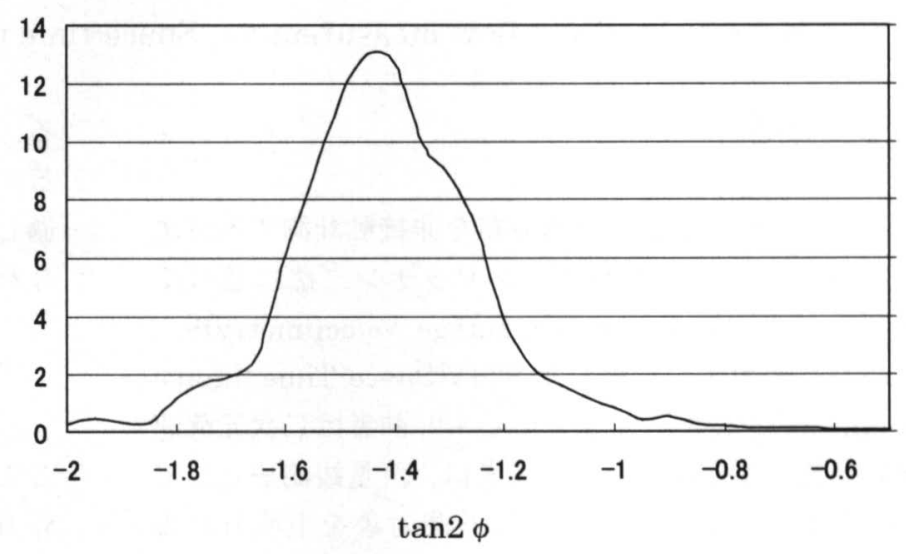

Fig. 2 Frequency Distribution

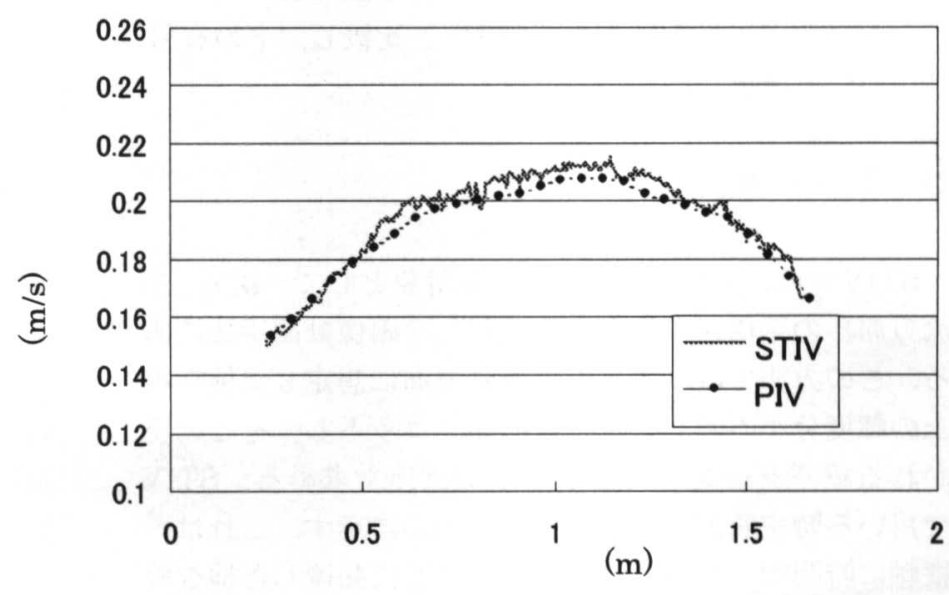

Fig. 3 Comparison of Mean Velocity Distribution 


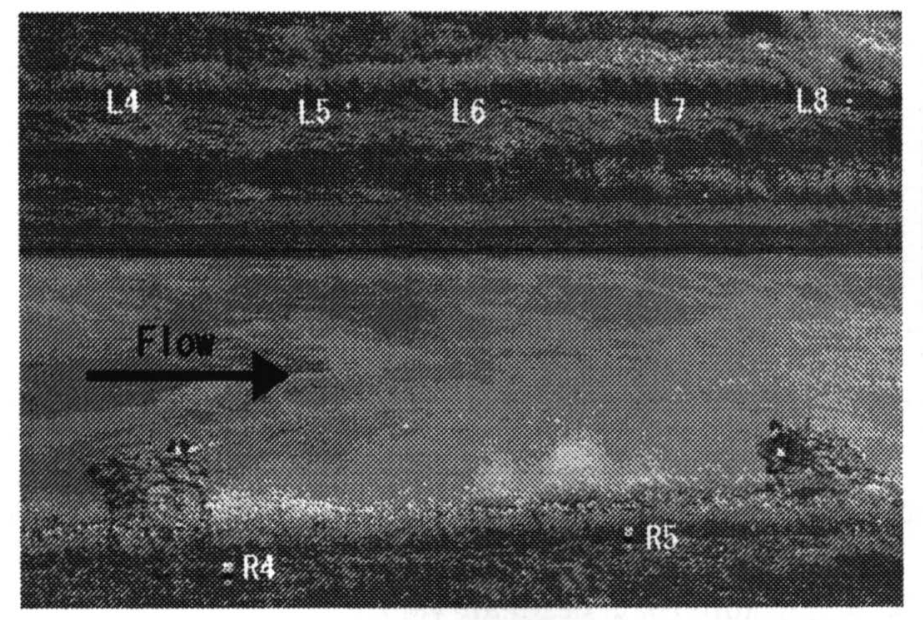

Table 1 Mark Point Coordinates

\begin{tabular}{|c|c|c|c|}
\hline 標定点 & X座票 (m) & Y座標 (m) & Z座標 (m) \\
\hline \hline R4 & 85.252 & -683.791 & 13.532 \\
\hline R5 & 88.241 & -702.566 & 13.525 \\
\hline L4 & 193.682 & -678.523 & 13.188 \\
\hline L5 & 191.929 & -695.338 & 13.009 \\
\hline L6 & 195.205 & -710.546 & 12.929 \\
\hline L7 & 193.947 & -730.249 & 13.053 \\
\hline L8 & 195.168 & -744.949 & 13.098 \\
\hline
\end{tabular}

Fig. 4 Surface Flow Image (the Uji River)

結果が示されている.データには多 少のばらつきはあるものの, 両者の 一致は良好であり, STIV において も十分流速計測が可能であることを 確認できた.

\section{4. 実河川流への適用}

\section{1 観測概要}

実河川を対象とした観測は淀川水 系宇治川 $42.8 \mathrm{kp}$ 付近(京都府京都市 伏見区)において行われた。Fig.4に 表面流の画像例を示す。表面には大 スケールのまだら模様が現われてお り，目視観測ではそれが主流に乗っ て下流に移流しているのが確認でき る.

撮影は観測用鉄塔の高さ $40 \mathrm{~m}$ の 地点から行った. 手前に見えている のは不透過型の水制（長さ $20 \mathrm{~m}$ ）で ある. 図中の R4 $5, \mathrm{~L} 4 \sim 8$ は標定 点であり, Table.1 に測量座標を示 した。これより, 対象となる空間ス ケールが数 10 メートルのオーダー であることがわかる. LSPIVによる 解析は $\Delta \mathrm{t}=1 / 3(\mathrm{sec}), \mathrm{STIV} に よ る$ 解析は $\Delta \mathrm{t}=1 / 30(\mathrm{sec}) 、$ 濃度勾配テ ンソルの積分サイズ $12 \times 12$ (pixel) とした。LSPIV、STIVとも 30 秒間 の画像データを用いて解析した。

\section{2 時空間プロットとコヒーレンシー分布}

実河川流が対象の場合には, トレーサーの散布が困難 なため, 前述のように表面に現われた水面の微小擾乱(波 紋）を一種のトレーサーと見たててその移流状況を追跡 する. 幸い, 観測地点では活発なボイルが発生しており,
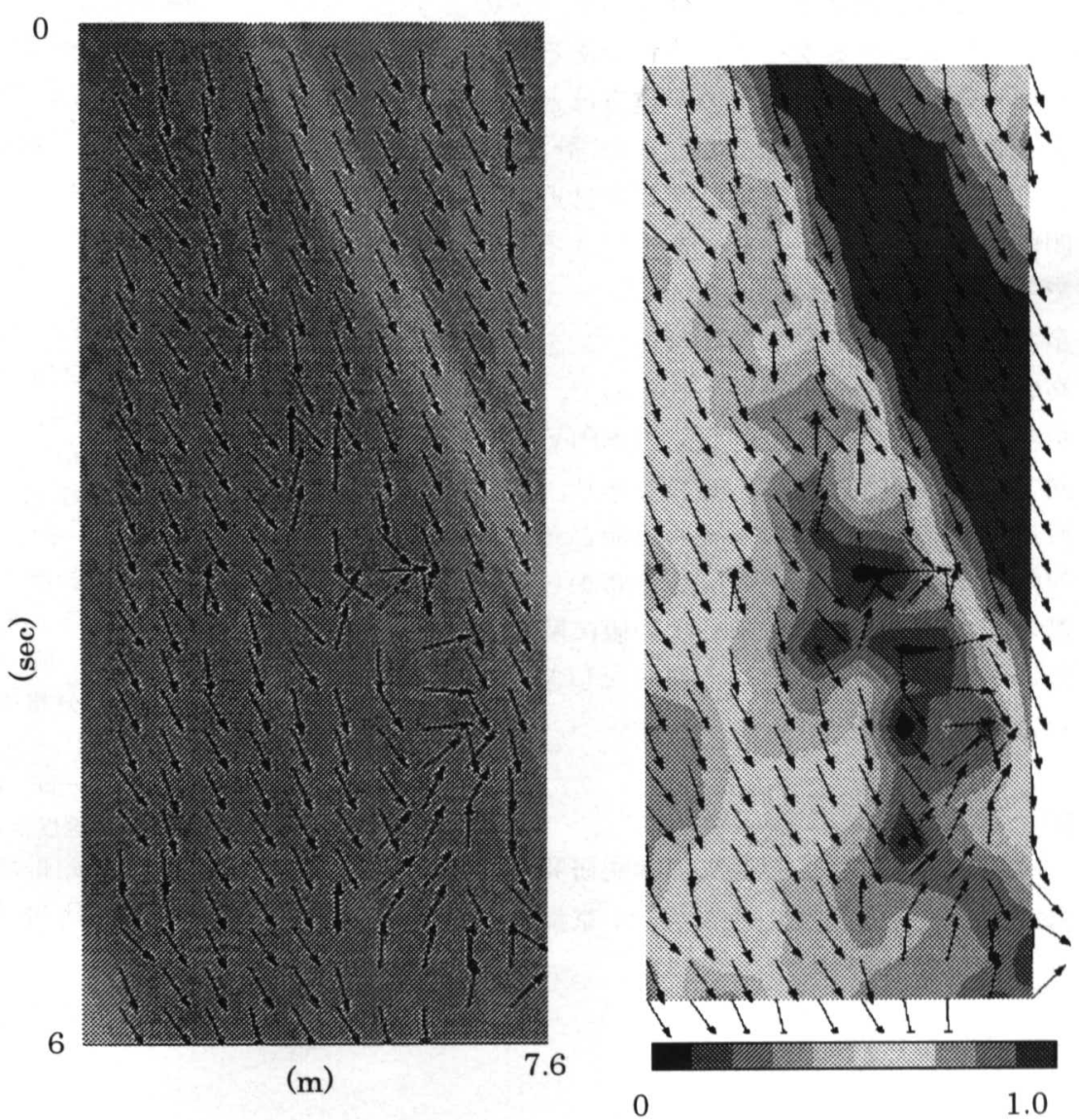

Fig. 5 Space-time Plot and Coherency Distribution

その痕跡を波紋として利用することができた，ある検査 線上の時空間プロットと STIV で得られた勾配ベクトル ならびにコヒーレンシーの分布を Fig. 5 に示す. 得られ た縞パターンは，トレーサーを用いた水路実験の時空間 プロットほど明瞭なものではないが，パターンが部分的 に得られているのは明らかであり,Fig.1の場合と同様, 
やはりコヒーレンシーの高い部分における 勾配ベクトルに一様性が見られる.

\section{3 解析結果}

Fig. 6 にSTIVとLSPIVによって得られ た平均流速分布の比較図を示す。両者はほ ぼ一致しており，実河川を対象とした場合 でもSTIVが十分に有効なことがわかる. ただし，手前の水制群の近くや水制間では 大規模な剥䧹渦が発生しており，流速の横 断方向成分の変動が大きくなるため, 今回 のSTIV 解析では計測の対象外とした。

\section{5.おわりに}

一般に, 河川流の撮影は, 堤防や橋の上 からの撮影が大半であり，今回のケースのように十分な 俯角が確保できるケースはまれである.LSPIVでは斜め 画像の幾何補正を行うため, 遠方ほど, 補正後の画像の 引き伸ばしが極端になってしまい, 計測精度が低下する。 従って, 撮影地点から離れた対岸付近でも横断方向の空 間解像度を 1 画素レベルで計測できる STIV は精度の点 でLSPIVよりも有利と思われる，また，画像にノイズ がある場合でも，最も強いパターンを示す模様に対して 高いコヒーレンシーが得られるので, この点でも優位性 がある，さらに，STIVでは，LSPIVよりも短い演算時 間で結果が得られる点も魅力であり，準リアルタイムの 河川流計測システムの構築も可能と考えられる.ただし， 勾配ベクトルの勾配值の度数分布から平均流速を求める 際の，コヒーレンシーのしきい值に関しては，その与え 方に任意性があるため，合理的なしきい值の決定法に関 しては今後の検討が必要である。

\section{謝 辞}

本研究は土木学会関西支部共同研究（研究代表 : 大阪 大学 出口一郎教授, メンバー: 京都大学防災研究所武

藤裕則助手, 近畿大学竹原幸生助教授, 高野保英助手, 明石高専神田佳一助教授）からの補助を得た。また，実 験に際しては各大学の学生諸君からの協力があった。こ こに記して謝意を表する.

\section{参 考 献}

1) Fujita, I., Muste, M. and Kruger, A. : Large-scale particle image velocimetry for flow analysis in hydraulic engineering applications, Journal of Hydraulic Research, IAHR, Vol.36, No. 3, (1998) pp. 397-414.

2）藤田一郎, 椿涼太 : 小俯角のビデオ画像に対忍した河川表 面流計測手法の開発，河川技術論文集，Vol. 7, (2001), pp. $475-478$.

3）藤田一郎, 椿涼太 : 時空間濃度勾配法による主流方向表面 流速分布 $の$ 現地計測，水工学铪文集，46 巻，（2002） pp. 821-826.

4）藤田一郎, 椿涼太 : 時空間画像を利用した河川表面波紋の 移流速度計測，河川技術論文集，Vol.9，(2003）pp. 55-60.

5) Jahne, B. : Spatio-Temporal Image Processing, Springer, (1993) pp. 150-152. 